\title{
A study protocol of mobile phone app- based cognitive behaviour training for the prevention of postpartum depression among high-risk mothers
}

\author{
Mei Sun ${ }^{1}$, Siyuan Tang ${ }^{1}$, Jiarui Chen ${ }^{1 *}$ (D), Ying Li', Wenhui Bai ${ }^{2}$, Virginia Plummer ${ }^{3,4,5}$, Louisa Lam,
} Chunxiang Qin ${ }^{1,6}$ and Wendy M. Cross ${ }^{5}$

\begin{abstract}
Background: The changes in China's family planning policy in recent years have led to changes in the age structure of pregnant women, and the prevalence of postpartum depression (PPD) is also on the rise. Cognitive Behaviour Training (CBT) as an effective intervention is widely used for postpartum depression. However, the shortage and health disparities of mental health resources, the stigma of postpartum depression in postpartum women and the need for postpartum recovery and child care prevent postpartum women from seeking traditional face-to-face CBT. Therefore, the purpose of this proposed study is to examine the effect of mobile phone applications (App) based CBT on postpartum depression, anxiety, pressure and parenting sense of competence.

Methods: A double blind, randomized controlled trial will be used in this study to examine the effectiveness of Appbased CBT in reducing the prevalence of postpartum depression compared with usual postpartum care in China. A total of 120 participants will be recruited in this study. The intervention consists of a weekly theme module app for continuous six weeks, each module including learning content and assignments. The control group received usual postpartum care content through the App. Outcome measures include postpartum depression, anxiety, pressure and parenting sense of competence at 0 -, 3- and 6-month after the intervention.
\end{abstract}

Discussion: If our intervention is effective, it will provide a time-friendly and unrestricted intervention for the psychological care of perinatal women, which can effectively solve the shortage and unevenness of mental health resources.

Trial registration: Chinese Clinical Trial Registry, ChiCTR1900020735. Registered 15 January 2019.

Keywords: Postpartum depression, Cognitive behaviour training, Mobile phone applications, Negative emotion symptoms, Parenting competence

\section{Background}

Mental health has become a global issue for public health. The global burden of disease 2016 (GBD 2016) confirmed that the major cause of non-fatal burden was mental disorders and substance use disorders, led by depressive disorders $[1,2]$. Postpartum depression (PPD) as a disabling but treatable mental disease is one of the

\footnotetext{
*Correspondence: chenjr@csu.edu.cn

'Xiangya Nursing School, Central South University, 172 Tongzipo Road Yuelu district, Changsha 410013, Hunan, China

Full list of author information is available at the end of the article
}

most common mental health issues faced by post-natal women. The Diagnostic and Statistical Manual of Mental Disorders, Fifth Edition (DSM-5) defines PPD as a major depressive episode that occurs during pregnancy or within 4 weeks of delivery [3]. This is because the effects of biological factors on women's emotions are significantly reduced impacted within 4 weeks after birth. However, the pressures of parenthood faced by some postpartum women are difficult to alleviate, and depression during this period continues to have negative consequences, which require medical treatment $[4,5]$.

(c) The Author(s). 2019 Open Access This article is distributed under the terms of the Creative Commons Attribution 4.0 International License (http://creativecommons.org/licenses/by/4.0/), which permits unrestricted use, distribution, and 
Therefore, in the current study focusing on PPD, the postpartum period is defined as one year after birth [6].

According to a report conducted by World Health Organization (WHO) [7], approximately $10 \%$ of pregnant women and $13 \%$ of women who have just given birth worldwide suffer from mental disorders, mainly depression. A recent meta-analysis of studies from 56 countries showed that the global prevalence of PPD is about $17.7 \%$ [8]. The national differences in the prevalence of PPD is mainly reflected in higher prevalence among women in lower-income and middle-income countries [9-11]. Studies in China in recent years have shown that the prevalence of PPD is approximately $25 \%$ $[12,13]$, which is higher than the global average. That may be partly due to the special condition of fertility policy in China. As an effective approach to decelerate the growth of population, the one-child policy has been implemented in China since the 1980s. Now the first generation of 'only children' following the implementation of that policy has reached reproductive age. Some research shows that women from one-child families are more likely to have PPD $[14,15]$. Moreover, with the recent change of family planning policy in China, many women have more than one child now. This has resulted in the changing age structure of pregnancy women, which is a clear factor for the increased proportion of advanced maternal age (AMA) [16]. This change may consequently increase the prevalence of PPD by increasing pregnancy complications as well other adverse pregnancy outcomes $[17,18]$.

As one of the most common mental health disorders during the postnatal period, the negative effects of PPD involve many aspects of daily life. These include lower quality of life for women [19], physical and psychological developmental disorders in children [20], and lower marital satisfaction [21]. Psychological interventions including health education, interpersonal psychotherapy (IPT), cognitive behaviour training (CBT) and problem focused therapy have been the main interventions for PPD due to concerns about the adverse effects of pharmacology therapy on breast feeding infants [22]. Among these psychological therapies, CBT is considered to be the most widely used. The effectiveness of CBT in mild to moderate depression has been demonstrated in many studies [23, 24]. Multiple guidelines and expert consensus also recommend CBT as an effective psychological intervention for PPD $[25,26]$. Nevertheless, there are still many barriers to the successful implementation of face to face CBT in the postpartum population. First, the shortage and health disparities of mental health resources, for example lack of mental health care workers, hinder the accessibility of mental health services [27]. Second, the stigma of PPD blocks seeking "face-to-face" mental health services, which are particularly prominent in lower-income and middle-income countries [28-30]. Lastly, the challenge of finding time for mothers to participate in the psychological intervention while trying to take care of their babies is also another barrier [27].

With the development of internet technology and mobile health in recent years, Computerised Cognitive Behavioural Therapy (CCBT) as well as health promotion mobile phone applications (App) have been used in many countries for the treatment of depression [31], anxiety [32] and insomnia [33]. In recent years, the continuous development of mobile communication networks and the wide application of smartphones have also provided new ways to realize psychological interventions based on mobile health technologies. It is reported that [34], as of June 2016, the number of mobile internet users in China reached 656 million, and the internet access equipment was further concentrated to the mobile terminal, which laid the foundation for the development of health services based on mobile health technology. CCBT and App-based CBT are easily accepted by postpartum women because of their flexibility in participation time and confidentiality of participant information. And for the providers of mental health services, CCBT and App-based CBT provide a good solution of the shortage of the mental health services resources. However, there is no currently CCBT or App-based CBT for women with PPD. Therefore, the purpose of this proposed study is to examine the effect of App-based CBT on psychosocial outcomes (including postpartum depression, anxiety, pressure and parenting sense of competence).

Based on this, we hypothesize that the App-based CBT will enable mental health services to be delivered to perinatal women in a more convenient, flexible and personalized way so that it can avoid the disadvantages of traditional CBT in terms of accessibility for perinatal women.

\section{Methods/design \\ Design}

A double blind, randomized controlled trial (RCT) will be used in this study. All participants who met the inclusion criteria were randomly assigned to the intervention group or control group for a six-week intervention program.

\section{Participants}

This study will be conducted in Changsha city, which has five administrative district. We will randomly select one health center from all the community health centers in each district. Participants will be recruited from five community health centers we selected. Inclusion criteria:

1) has Established maternal health care record in community health centers; 
2) 0 days to 6 weeks after delivery;

3) Score of 9-12 on the Edinburgh Postnatal Depression Scale (EPDS);

4) Access to smart phone and able to independently use App;

5) Informed consent and voluntary participation.

Exclusion criteria:

1) Severe mental disorders (current or in the past);

2) History of brain injury, intellectual disability or cognitive disorder; and

3) Undergoing psychotherapy or any other psychological intervention.

4) Patients diagnosed with postpartum depression or other severe mental illness during the study.

\section{Measures}

Measurements will be obtained at baseline $\left(t_{0}\right)$, immediately after the last intervention $\left(t_{1}\right), 3$ months following the intervention $\left(t_{2}\right)$ and 6 months following the intervention $\left(t_{3}\right)$. The baseline data is collected when participants are enrolled, and after that, the data collection process will be implanted in the evaluation module of the mobile App. The primary outcome will be depression status. The secondary outcomes will be negative emotion symptoms including depression, anxiety and stress, parenting confidence. These will be measured as follows:

1. Demographic and Socioeconomic factors: the information about Risk factors will be collected by demographic questioner including pregnancy and birth history, obstetric complications, delivery mode, baby gender, baby weight, baby health status, feeding pattern, satisfaction with family care, major life events. The socioeconomic factors include maternal age, marital status, history of depression, family history of mental disorder, occupation, medical insurance, education level, family income, and religious belief.

2. Depression status: We will use the Edinburgh Postnatal Depression Scale (EPDS) Chinese version to assess participant's depressive status, as this scale is an effective self-screening tool for PPD. The EPDS to be used in this study was translated by Lee [35] the sensitivity was $82 \%$, the specificity was $86 \%$, the positive predictive value was $44 \%$, and the negative predictive value was $97 \%$. The scale includes 10 items. The recommended threshold is $<$ 9: no depression; 9 is regarded as a probable case; and 13 or more as suspected depression.

3. Negative emotion symptoms: We will assess negative emotion symptoms using the Depression, Anxiety and Stress Scale (DASS-21), which is a self-report measure of anxiety, depression and stress levels used in diverse settings developed by Lovibond [36]. The Chinese version of DASS-21 was developed by Taouk ${ }^{[40]}$ in 2001. This version was tested in Australian-Chinese speaking samples and Hong Kong-Chinese speaking samples, and indicated that the items had been adequately and appropriately translated and adapted. Wen Yi et al. [37] tested DASS-21 in 730 Chinese adults (over 18 years old), the result showed that the Cronbach's $\alpha$ was 0.912 and the test-retest Pearson correlation coefficient was 0.751.

4. Parenting competence: Parenting competence will be assessed using the Chinese version of Parenting Sense of Competence Scale (C-PSOC). The initial Parenting Sense of Competence Scale was an English version developed by Gibaud-Wallston [38]. In 2014 Chinese researcher, Yang Xiao translated it into Chinese and applied to Chinese population. C-PSOC includes efficacy and satisfaction factors and has 17 items. The Cronbach's coefficient, efficacy factor and satisfaction factor of C-PSOC were $0.82,0.80$ and 0.85 respectively [39].

\section{Conditions}

\section{The intervention condition: app-based CBT}

App-based CBT is comprehensive App that including investigation and intervention. The investigation section includes four surveys (baseline, immediately after the intervention, three months after the intervention and six months after the intervention). The content of investigation is mentioned in the measures section. Taking into account the needs for women to rest and care for their newborns after giving birth, in order to ensure the effectiveness of the intervention, our research team conducted a survey of the needs of mental health services for postpartum women before determining specific interventions. Based on this result, we developed intervention program. The intervention consists of six modules, participants need to complete one module each week for six consecutive weeks, and each module will takes an average of $30-40 \mathrm{~min}$. Participants will receive a reminder if they haven't started reading the content of each module for the fourth day after the module is opened. Module 1 (prologue) will help participants to gain a preliminary understanding of postpartum depression. Module 2 (emotion) will help participants understand the negative emotions and identify them. Module 3 (recognition) will assist participants recognize the erroneous thinking. Module 4 (amendment) will provide some strategies for participants to deal with the biased habitual thinking. Module 5 (rebound) will help participants focus on the present life and avoid immersing in 
negative emotions. Module 6 (remain happiness) will help participants review the techniques of emotion management and getting rid of biased thinking, so that they can keep happy (Table 1).

\section{Control condition}

Participants in control group will also complete six health education modules which are formulated according to the standard of health management service postpartum and the child health management through the App. It mainly includes the care of postpartum perineum incision and caesarean section wounds, breast or bottle feeding, postpartum recovery, neonatal care (bath and touch), neonatal vaccination and postpartum reproductive health (contraception) (Table 1).

\section{Sample size}

A power analysis was performed for linear regression using University Dusseldorf G*Power 3.1 to determine the sample size necessary for analysis. The main objective of this study is to assess the effectiveness of App-based CBT on PPD high-risk mothers. According to previous studies, an effect size of 0.43 will be adopted [40]. The power analysis based on the conventional significant alpha level of 0.05 and a power of 0.90 using a two-tailed test. We calculate that the sample size required is 48 in each group. Considering a $20 \%$ dropout rate, the recruited sample size required in each group is 60.

\section{Procedure}

For the participants who meet the inclusion criteria, the researchers will introduce the research content to them to confirm their willingness to participate in the study. Participants will also be asked whether they understand the benefits and possible risks involved in this study. For participants who agree to join in the study, the researchers will ask them to download the App and researchers will issue an informed consent form and inform participants that they will be randomly assigned to different groups, and all the individuals have the right to consult to researchers. If the participant does not agree to be involved in the study, the researchers will record the reasons for their refusal. The schedule of enrolment, interventions, and assessments are summarized in Table 2. If the intervention was shown to be effective, participants in the control group would receive the intervention immediately after the study was completed.

Table 1 The conditions between intervention group and control group

\begin{tabular}{|c|c|c|}
\hline Time & Intervention group & Control group \\
\hline 1 week & $\begin{array}{l}\text { Prologue will help participant to understand the postpartum } \\
\text { depression } \\
\text { a. Using examples to introduce what is postpartum depression, } \\
\text { PPD symptoms, and how to differentiate PPD with the normal } \\
\text { changes which might happen after delivery } \\
\text { b. New progress of the treatment and intervention of PPD } \\
\text { c. Skill learning: Self-evaluate the status of PPD }\end{array}$ & $\begin{array}{l}\text { a. Postpartum perineum incision care or caesarean section } \\
\text { wounds; } \\
\text { b. Explanation of lochia postpartum; } \\
\text { c. Prevention of postpartum constipation }\end{array}$ \\
\hline 2 week & $\begin{array}{l}\text { Emotion will help participants } \\
\text { a. Understand what negative emotions is. } \\
\text { b. Record negative emotions and the corresponding } \\
\text { behavioral responses } \\
\text { c. Skill learning: think differently }\end{array}$ & $\begin{array}{l}\text { Neonatal feeding (breast feeding or bottle feeding) } \\
\text { a. Encourage breastfeeding, and how to breastfeeding } \\
\text { correctly. } \\
\text { b. Identify situations that require bottle feeding }\end{array}$ \\
\hline 3 week & $\begin{array}{l}\text { Recognition will assist participants understand } \\
\text { a. What is the biased habitual thinking? } \\
\text { b. What is the relationship between biased habitual thinking } \\
\text { and negative emotions? } \\
\text { c. Skill learning: identify the biased habitual thinking. }\end{array}$ & $\begin{array}{l}\text { Neonatal care (bathing and touch) } \\
\text { a. Time, temperature and supplies of bathing; } \\
\text { b. Navel nursing } \\
\text { c. Neonatal touch method }\end{array}$ \\
\hline 4 week & $\begin{array}{l}\text { Amendment will provide some strategies for participants to } \\
\text { deal with the biased habitual thinking } \\
\text { a. Using example to help participants understand what is the } \\
\text { consequences of the biased habitual thinking. } \\
\text { b. How to divert their attentions from the troublesome thing. } \\
\text { c. Skill learning: introspect your thinking. }\end{array}$ & $\begin{array}{l}\text { Postpartum recovery (early training) } \\
\text { a. The timing and frequency of getting out of bed } \\
\text { b. Intensity of postpartum exercise }\end{array}$ \\
\hline 5 week & $\begin{array}{l}\text { Rebound will help participants focus on the present life and } \\
\text { avoid immersing in negative emotions. } \\
\text { a. Record the daily life } \\
\text { b. Balance your life } \\
\text { c. Skill learning: Set short-term goals and long-term goals and }\end{array}$ & $\begin{array}{l}\text { neonatal vaccination } \\
\text { a. Knowledge of infant vaccination }\end{array}$ \\
\hline 6 week & $\begin{array}{l}\text { Remain happiness will help participants } \\
\text { a. Review the techniques of emotion management and getting } \\
\text { rid of biased thinking } \\
\text { b. Skill learning: Record the daily happy things }\end{array}$ & $\begin{array}{l}\text { postpartum reproductive health (contraception) } \\
\text { a. Choice of contraceptive methods }\end{array}$ \\
\hline
\end{tabular}


Table 2 The timeline of enrolment, interventions and assessments

\begin{tabular}{|c|c|c|c|c|c|c|c|c|c|c|c|}
\hline \multirow[b]{3}{*}{ Timepoint } & \multicolumn{11}{|c|}{ Study period } \\
\hline & \multirow[t]{2}{*}{ Enrolment } & \multirow{2}{*}{$\begin{array}{l}\text { Allocation } \\
t_{0}\end{array}$} & \multicolumn{6}{|c|}{ Intervention } & \multicolumn{3}{|c|}{ Follow-up } \\
\hline & & & 1st week & 2nd week & 3rd week & 4th week & 5th week & 6th week & $t_{1}$ & $t_{2}$ & $\mathrm{t}_{3}$ \\
\hline \multicolumn{12}{|l|}{ Enrolment: } \\
\hline eligibility screen & $\bullet$ & & & & & & & & & & \\
\hline informed consent & $\bullet$ & & & & & & & & & & \\
\hline allocation & & $\bullet$ & & & & & & & & & \\
\hline \multicolumn{12}{|l|}{ Interventions: } \\
\hline intervention group & & & • & $\bullet$ & $\bullet$ & $\bullet$ & $\bullet$ & $\bullet$ & & & \\
\hline control group & & & $\bullet$ & $\bullet$ & $\bullet$ & $\bullet$ & • & • & & & \\
\hline \multicolumn{12}{|l|}{ Assessments: ${ }^{*}$} \\
\hline baseline & & $\bullet$ & & & & & & & & & \\
\hline immediately after the last intervention & & & & & & & & & $\bullet$ & & \\
\hline 3 months following the intervention & & & & & & & & & & $\bullet$ & \\
\hline 6 months following the intervention & & & & & & & & & & & $\bullet$ \\
\hline
\end{tabular}

*Variables assessed at baseline include demographic factors, socioeconomic factors, depression status, negative emotion symptoms, parenting competence *Variables assessed at other three times are the same, they were depression status, negative emotion symptoms, parenting competence

\section{Randomization}

The allocation scheme is generated by the random digital program. The whole randomization process is a computer-based algorithm. The starting value will be determined by the current server time and the process of the allocation scheme will be recorded for replication. Randomization will not be stratified and will occur automatically at the completion of the baseline survey by obtaining the next allocation of the generated timeline.

\section{Blinding}

This study will be a double-blind trial. After the baseline survey is completed, the allocation scheme will be generated by a computer program and it will be kept in closed and opaque envelopes and saved by the researchers who have no direct relationship with the project to ensure that the random allocation scheme is hidden in advance. The automatic randomization allocation of the participants will remain blind to the enrolling researcher. Researchers who administered the six-week intervention and analyzed the data were also blind to the grouping. Participants will be informed that this study is to investigate the effectiveness of an App-based intervention program to protected women from PPD, but they will not be informed of anything content related to the specific interventions.

\section{Analysis}

This study used double data entry. Data entrants, analysts, and data custodians do not participate in the intervention process. Analyses will be performed using SPSS (version 20.0; SPSS Inc., Chicago, Ill). All tests of significance will be determined at an alpha level of 0.05. The principle of ITT will be used to handle missing data. We plan to analyse contrasts between intervention and control groups at baseline, post intervention, 3 months and 6-months follow-up.

\section{Ethical approval}

The plan and the design content have been reviewed and approved by Institutional Review Board (IRB) of University (IRB Approval Number: 2018004). Researchers will introduce this program, including the research process, benefits and possible risk of this study, as well as the voluntary nature of the study, to those women who meet inclusion criteria. A written informed consent will also be obtained. Participants have the right to withdraw at any time.

\section{Risk management}

In our study, participants have to complete EPDS at baseline, immediately after the intervention, three months after the intervention, and six months after the intervention. We will refer the participants to psychologist immediately after we found participants who had EPDS scores greater than 12. Each participant is entitled to withdraw from the study during the intervention, when they decided to withdraw from the study, our research team will assess their situation to see if they needed to be transferred to psychologist.

\section{Discussion}

In China, although existing maternal health care regulations clearly propose to provide mental health services during pregnancy and postpartum, most of those services are carried out in hospitals, which reduce their 
accessibility to some women especially in the postpartum period. There are some health programmes for pregnant women organized by the hospital or community which provide information about mental health, but that is only for pregnant women with no follow-up available. With the advancement of graded diagnosis and treatment of public health, postnatal home visits have become a routine service for community work [41]. Usually, during the first 6 weeks following childbirth community medical professionals will conduct regular visits but the mental health status is not included in the visit. Therefore, developing a systematic, continuous, and accessible psychological intervention is essential. To the best of our knowledge, this proposed study will be the first intervention study to apply CBT to women with PPD through mobile health technology.

The highlight of this study was the application of App-based CBT to postpartum women. Ensuring the effectiveness of intervention is the key to this study. Firstly, the provider of intervention must be professionally trained and supervised $[42,43]$. In our research, the intervention program was developed with the participation of psychologists to ensure the professionalism of the CBT program. Secondly, we conducted a survey on the form, frequency, and duration of intervention before the intervention was made to ensure the feasibility of intervention. Within those, the effectiveness and operability of interventions will be guaranteed.

In recent years, the high prevalence of postpartum depression in China and the shortage of mental health service resources make it extremely urgent to effectively intervene postpartum depression. With the development of mobile health technology, this study provides a convenient and effective intervention measure for postpartum depression women. If our intervention program proves to be effective in reducing the prevalence of postpartum depression, this will not only provide convenient and effective intervention measures for postpartum depression and effectively saved mental health service resources, but will also provide evidence-based evidence for interventions based on mobile health technologies.

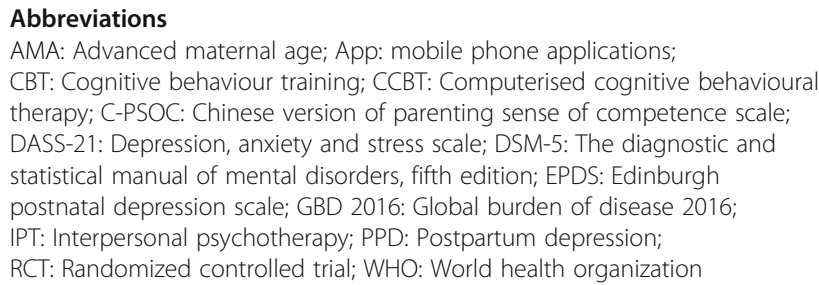

Acknowledgements

Not applicatable.

\section{Funding}

This study is supported by Humanities and social sciences fund of the Ministry of Education (18YJC840033). The aim, process and budget of the study was discussed with the sponsor. The sponsor had no role in the preparation of this manuscript, design of the study, collection, management, analysis or interpretation of data and the decision to publish.

\section{Availability of data and materials}

The datasets used and/or analysed during the current study are available from the corresponding author on reasonable request.

\section{Authors' contributions}

MS, ST, JC, YL, WB, WC, CQ were responsible for the conception and design of study; VP, LL were responsible for statistics consultation; MS, JC were responsible for drafting the manuscript; WC, VP, LL were responsible for revising the manuscript critically for important intellectual content. All the authors have read the manuscript and approval of the version of the manuscript to be published.

\section{Ethics approval and consent to participate}

The plan and the design content have been reviewed and approved by Institutional Review Board (IRB) of behavioural and nursing research in School of Nursing of CSU (IRB Approval Number: 2018004). A written informed consent will also be obtained.

\section{Consent for publication}

Not applicable.

\section{Competing interests}

Authors have read BioMed Central's guidance on competing interests and declare that none of the authors have any competing interests.

\section{Publisher's Note}

Springer Nature remains neutral with regard to jurisdictional claims in published maps and institutional affiliations.

\section{Author details}

'Xiangya Nursing School, Central South University, 172 Tongzipo Road Yuelu district, Changsha 410013, Hunan, China. ${ }^{2}$ Henan Provincial People's Hospital, Zhengzhou 450000, China. ${ }^{3}$ School of Nursing and Midwifery, Monash University, Melbourne, VIC 3800, Australia. ${ }^{4}$ Peninsula Health, Frankston, VIC 3199, Australia. ${ }^{5}$ School of Nursing and Healthcare Professions, Federation University, Melbourne, VIC 3806, Australia. ${ }^{6}$ Obstetrical Department, The Third Xiangya Hospital, Central South University, Changsha 410013, China.

Received: 15 February 2019 Accepted: 7 May 2019

Published online: 07 June 2019

\section{References}

1. Vos T, et al. Global, regional, and national incidence, prevalence, and years lived with disability for 328 diseases and injuries for 195 countries, 19902016: a systematic analysis for the Global Burden of Disease Study 2016. Lancet. 2017;390(10100):1211-59.

2. Network, G.B.o.D.C., Global Burden of Disease Study 2016 (GBD 2016) Causes of Death and Nonfatal Causes Mapped to ICD Codes., in Institute for Health Metrics and Evaluation (IHME). 2017.

3. American Psychiatric, A., D.S.M.T.F. American Psychiatric Association, and P American Psychiatric. In: Diagnostic and statistical manual of mental disorders : DSM-5. 5th ed. ed. DSM-5. Arlington, VA: American Psychiatric Association; 2013

4. Stuart-Parrigon K, Stuart S. Perinatal Depression: an update and overview. Curr Psychiatry Rep. 2014:16(9):1-9.

5. Wisner K, Moses-Kolko E, Sit D. Postpartum depression: a disorder in search of a definition. Off J Section Women's Health World Psychiatr Assoc. 2010; 13(1):37-40

6. O'Hara MW, Wisner KL. Perinatal mental illness: definition, description and aetiology. Best Pract Res Clin Obstet Gynaecol. 2013;28(1):3-12

Organization, W.H. Mental health ATLAS 2017; 2018. p. 68.

8. Hahn-Holbrook, J., T. Cornwell-Hinrichs, and I. Anaya, Economic and health predictors of National Postpartum Depression Prevalence: a systematic review, meta-analysis, and Meta-Regression of 291 Studies from 56 Countries, in Front. Psychiatry. 2018.

9. Gavin IN, et al. Perinatal Depression: a systematic review of prevalence and incidence. Obstet Gynecol. 2005;106(5, Part 1):1071-83. 
10. Parsons $C E$, et al. Postnatal depression and its effects on child development: a review of evidence from low- and middle-income countries. Br Med Bull. 2012;101(1):57-79.

11. Fisher J, et al. Prevalence and determinants of common perinatal mental disorders in women in low- and lower-middle-income countries: a systematic review. Bull World Health Organ. 2012;90(2):139.

12. Chi $X$, et al. Screening for postpartum Depression and associated factors among women in China: a cross-sectional study.(survey). Front Psychol. 2016;7:1-8.

13. Zhou C, et al. Social capital and antenatal depression among Chinese primiparas: a cross-sectional survey. Psychiatry Res. 2017;257:533-9.

14. Deng A-W, et al. Prevalence and risk factors of postpartum depression in a population-based sample of women in Tangxia community, Guangzhou. Asian Pac J Trop Med. 2014;7(3):244-9.

15. Ribo $X$, et al. Prevalence and factors associated with postpartum depression in women from single-child families. Int J Gynecol Obstet. 2018;141(2):194-9.

16. Kang C, et al. The Influence of the New Fertility Policy on Size and Structure of Maternity in Obstetric and Gynecologic Hospitals. Popul Res. 2015;39(6):85-93.

17. Lean, S.C., et al., Advanced maternal age and adverse pregnancy outcomes: A systematic review and meta-analysis, in PLoS One. 2017.

18. Koutra K, et al. Pregnancy, perinatal and postpartum complications as determinants of postpartum depression: the Rhea mother-child cohort in Crete, Greece. Epidemiol Psychiatr Sci. 2018;27(3):244-55.

19. Feki. R., et al., Impact of postpartum depression on quality of life. Eur Psychiatry. 2017:S901-2.

20. Farías-Antúnez S, Xavier MO, Santos IS. Effect of maternal postpartum depression on offspring's growth. J Affect Disord. 2018;228:143-52.

21. Clout D, Brown R. Marital relationship and attachment predictors of postpartum stress, anxiety, and depression symptoms. J Soc Clin Psychol. 2016;35(4):322-41.

22. Eberhard-Gran M, Eskild A, Opjordsmoen S. Use of psychotropic medications in treating mood disorders during lactation. CNS Drugs. 2006;20(3):187-98.

23. Jesse $D E$, et al. Performance of a culturally tailored cognitive-behavioral intervention integrated in a public health setting to reduce risk of antepartum Depression: a randomized controlled trial. J Midwifery Women's Health. 2015;60(5):578-92.

24. Farrand P, Woodford J. Effectiveness of cognitive Behavioural self-help for the treatment of Depression and anxiety in people with long-term physical health conditions: a systematic review and meta-analysis of randomised controlled trials. Ann Behav Med. 2015:49(4):579-93.

25. Vigod SN, Stewart DE, Depression P. N Engl J Med. 2017;376(9):895.

26. Gelenberg A, et al. PRACTICE GUIDELINE FOR THE Treatment of Patients With Major Depressive Disorder Third Edition. Am J Psychiatry. 2010;167(10): 1-3 9-11,13-118.

27. Patel $V$, et al. The magnitude of and health system responses to the mental health treatment gap in adults in India and China. Lancet. 2016;388(10063): 3074-84.

28. Thomas $\sqcup$, Scharp KM, Paxman CG. Stories of postpartum Depression: exploring health constructs and help-seeking in mothers' talk. Women Health. 2014;54(4).

29. O'mahen $\mathrm{AH}$, et al. Stigma and Depression during pregnancy: does race matter? J Nerv Ment Dis. 2011;199(4):257-62.

30. Baker-Ericzen MJ, et al. A collaborative care telemedicine intervention to overcome treatment barriers for Latina women with depression during the perinatal period. Fam Syst Health. 2012;30(3):224.

31. Klein JP, et al. Time to remission from mild to moderate depressive symptoms: one year results from the EVIDENT-study, an RCT of an internet intervention for depression. Behav Res Ther. 2017;97:154-62.

32. March S, Spence SH, Donovan CL. The efficacy of an internet-based cognitive-behavioral therapy intervention for child anxiety disorders. J Pediatr Psychol. 2009;34(5):474-87.

33. Coulson N, et al. The pros and cons of getting engaged in an online social community embedded within digital cognitive behavioral therapy for insomnia: survey among users. J Med Internet Res. 2016;18(4):E88.

34. Chang-hai $\mathrm{H}$. Analysis of the smart phone market in the first half of 2016. China Internet. 2016;13(10):74-6.

35. Lee $\mathrm{D}$, et al. Detecting postnatal depression in Chinese women. Validation of the Chinese version of the Edinburgh postnatal Depression scale. Br J Psychiatry. 1998;172:433-7.
36. Lovibond PF, Lovibond SH. The structure of negative emotional states: comparison of the Depression anxiety stress scales (DASS) with the Beck Depression and anxiety inventories. Behav Res Ther. 1995;33(3):335-43.

37. Wen Y, Da-Xing WU, Xue-Jing L. Psychometric properties of the Chinese short version of Depression anxiety and stress scale in Chinese adults. Chin J Public Health. 2012.

38. Gibaudwallston, J., Self-esteem and situational stress: factors related to sense of competence in new parents. Wallston, 1978.

39. Xiao $Y$, et al. The reliability and validity of the Chinese version of parenting sense of competence scale. Chin J Nurs. 2014;7:881-5.

40. Jones BA, et al. Online cognitive behaviour training for the prevention of postnatal depression in at-risk mothers: a randomised controlled trial protocol. BMC Psychiatry. 2013;13(1):265.

41. Commission, N.H.a.F.P. National standards for basic public health services (third edition). 2017: Available from: http://www.nhc.gov.cn/jws/s3578/ 201703/aefef3d0b2a14279b76ad57d7e7a2c4e.shtml.

42. Rahman A, et al. Interventions for common perinatal mental disorders in women in low- and middle-income countries: a systematic review and meta-analysis. In: Bull. World health organ; 2013. p. 593-601.

43. Pugh N, et al. Client experiences of guided internet cognitive behavior therapy for postpartum depression: a qualitative study. Off J Section Women's Health World Psychiatr Assoc. 2015;18(2):209-19.

\section{Ready to submit your research? Choose BMC and benefit from:}

- fast, convenient online submission

- thorough peer review by experienced researchers in your field

- rapid publication on acceptance

- support for research data, including large and complex data types

- gold Open Access which fosters wider collaboration and increased citations

- maximum visibility for your research: over $100 \mathrm{M}$ website views per year

At BMC, research is always in progress.

Learn more biomedcentral.com/submissions 